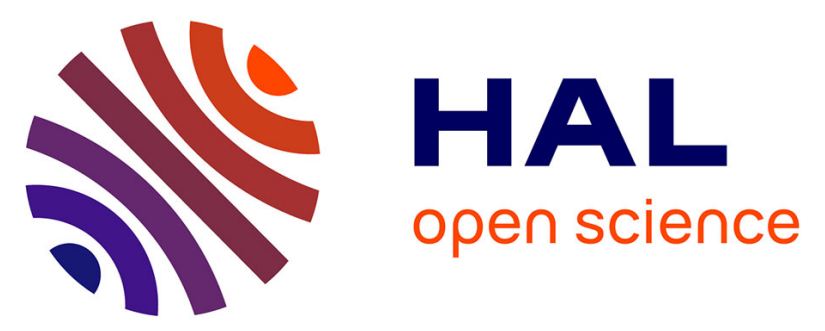

\title{
Amphiprotism-Coupled Near-Infrared Emission in Extended Pyrazinacenes Containing Seven Linearly Fused Pyrazine Units
}

Gary J Richards, Aël Cador, Shinji Yamada, Anna Middleton, Whitney A Webre, Jan Labuta, Paul A Karr, Katsuhiko Ariga, Francis d'Souza, Samia Kahlal, et al.

\section{To cite this version:}

Gary J Richards, Aël Cador, Shinji Yamada, Anna Middleton, Whitney A Webre, et al.. Amphiprotism-Coupled Near-Infrared Emission in Extended Pyrazinacenes Containing Seven Linearly Fused Pyrazine Units. Journal of the American Chemical Society, 2019, 141 (50), pp.19570-19574. 10.1021/jacs.9b10952 . hal-02397311

HAL Id: hal-02397311 https://hal-univ-rennes1.archives-ouvertes.fr/hal-02397311

Submitted on 11 Dec 2019

HAL is a multi-disciplinary open access archive for the deposit and dissemination of scientific research documents, whether they are published or not. The documents may come from teaching and research institutions in France or abroad, or from public or private research centers.
L'archive ouverte pluridisciplinaire HAL, est destinée au dépôt et à la diffusion de documents scientifiques de niveau recherche, publiés ou non, émanant des établissements d'enseignement et de recherche français ou étrangers, des laboratoires publics ou privés. 
Pyrazinacenes ${ }^{1,2}$ contain multiple 1,4-pyrazine units linearlyfused through $\mathrm{C}-\mathrm{C}$ bonds so that the nitrogen atoms are contained at the apical positions of the acene framework. Higher analogues tend to contain a single reduced dihydropyrazine because of the relative electron deficiency of these highly nitrogenous chromophore molecules. ${ }^{1-3}$ On the other hand, chromophore-based bio-imaging techniques rely on the availability of dyes that are emissive in regions of the electromagnetic spectrum not obscured by absorptive processes of biomolecules or water. ${ }^{4,5}$ Thus, dyes emitting in the near-infrared transparency window region of tissues from 650-900 $\mathrm{nm}$ are useful for imaging, ${ }^{6}$ also allowing good tissue penetration without significant risk of damage caused by ultraviolet light. It is also advantageous if excitation and emission wavelengths of a particular chromophore lie within this region with the additional benefit that tissue autofluorescence is minimized. Several classes of dye meet these requirements including cyanines (e.g., ICG) ${ }^{7}$, BODIPY $^{8}$ and porphyrins. ${ }^{9}$ Despite the availability of these dyes, the development of new synthetically flexible dyes as NIR-emitting

\begin{abstract}
Peripherally substituted tetradecaazaheptacene $\left(\mathrm{N}_{14} \mathrm{Hp}\right) \quad$ compounds, exhibiting amphiprotism-coupled
emission, have been synthesized. X-ray crystallography reveals a planar acene-like chromophore, and electronic absorption window $(650-900 \mathrm{~nm})$. The compounds exhibit long wave emission with photoluminescence quantum yields $\Phi_{\mathrm{PL}}$ up to $\sim 0.61$ at $686 \mathrm{~nm}$ with monodeprotonated state $\Phi_{\mathrm{PL}} \sim 0.58$ at illustrates the stability and utility of the pyrazinacenes for different applications based on their photophysical properties and chemical structures.
\end{abstract}

chromophores remains an important goal. With this in mind, we have developed the synthesis of pyrazinacene chromophores whose excitation and emission spectra fall within the tissue transparency window and whose quantum yields of fluorescence make them of significant interest for various applications.

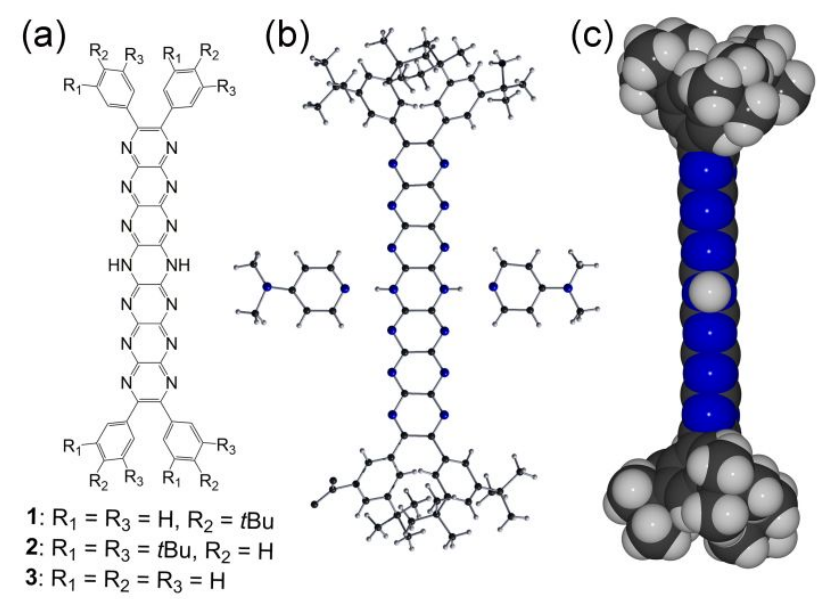

Figure 1. (a) Chemical structures of the 7,16-dihydro1,4,5,6,7,8,9,10,13,14,15,16,17,18-tetradecaazaheptacene derivatives $\mathbf{1}$ and $\mathbf{2}$. Structure $\mathbf{3}$ was used for computational purposes. (b) X-ray crystal structure of 2 . Two 4-DMAP molecules are hydrogen bonded $\left(\mathrm{N}_{14} \mathrm{Hp}\right.$... $\left.\mathrm{N}_{\text {DMAP }} 2.69 \AA\right)$ at central dihydropyrazine. (c) Space-filling model viewed perpendicular to pyrazinacene plane.

Here we report the synthesis, amphiprotism and NIR emissive properties of an extended pyrazinacene chromophore containing 7 linearly-fused pyrazine units, i.e., tetradecaazaheptacene. Synthesis of $\mathbf{1}$ and $\mathbf{2}$ (Figure 1) was 
achieved by the respective condensation of the appropriately substituted pyrazinopyrazine-2,3-dicarbonitrile with pyrazine-2,3,5,6-tetraamine. ${ }^{10}$ This reaction ought to supply the tetrahydro derivatives but the corresponding dihydro derivatives were isolated. This is due either to autoxidation of the initial product or reaction of already oxidized derivatives of pyrazinetetramine. Final products were isolated in poor to moderate yields of around $16 \%$ due to the requirement for a double condensation and the low stability of the pyrazinetetramine precursor. Solubilizing substituents were attached at the terminal carbon atoms of the tetradecaazaheptacene core rather than at nitrogen atoms in order to allow study of protic processes (protonation/deprotonation). The X-ray crystal structure of $\mathbf{2}$ is shown in Figure 1b, c (see also Figures S1, S2). Crystals were grown from solutions containing 4-dimethylaminopyridine (4DMAP) to disclose the positions of the protons on the tetradecaazaheptacene $\left(\mathrm{N}_{14} \mathrm{Hp}\right)$ backbone (triethylamine (TEA) was also used for this purpose but gave only poor quality crystals although the connectivity of its $\mathrm{N}_{14} \mathrm{Hp}$ backbone could still be established - Figures S3, S4). Two DMAP molecules per $\mathrm{N}_{14} \mathrm{Hp}$ are clearly contained hydrogen bonded $\left(\mathrm{N}_{14} \mathrm{Hp} \ldots \mathrm{N}_{\text {DMAP }}\right.$ $2.69 \AA$ suggests a moderately strong interaction) with the structure of the central unit confirming that the dihydropyrazine compound was isolated. 2.DMAP 2 units are arranged in the crystal with dimethylamino groups separating the $\mathrm{N}_{14} \mathrm{Hp}$ units (short contacts suggesting $\mathrm{CH} . . . \pi$ and $\mathrm{CH} . . \mathrm{N}$ interactions). Planes of the $\mathrm{N}_{14} \mathrm{Hp}$ chromophores are separated by $\sim 6.8 \AA$.

Basic photophysical properties of the compounds are summarized in Figures 2, 3 and Table 1. Tertiary-butyl substituted compounds exhibit an absorption $\lambda_{\max }$ around 674 $\mathrm{nm}$ in methanol with a typical acene vibronic structure. The absorption edge at around $723 \mathrm{~nm}$ equates to an optical gap of $1.71 \mathrm{eV}$, very close to that of CH-only hexacene $(1.79 \mathrm{eV}) .{ }^{11}$ Fluorescence emission occurs with a small Stokes shift of 20 $\mathrm{nm}$. The excitation spectra of the neutral compounds in THF (Figure S5) are essentially identical with their absorption spectra, suggesting predominance of a single non-aggregated species, despite the possibility of numerous other tautomeric forms. ${ }^{12}$ In low polarity solvents such as dichloromethane or toluene, acene-type spectra of $\mathbf{1}$ are replaced by a broad, hypsochromically shifted absorption at $604 \mathrm{~nm}$, most likely as a result of aggregation (see Figure S6, S7). Aggregation of 1 under these conditions is also evident from ${ }^{1} \mathrm{H}$ NMR spectra, which reveal significant broadening of aromatic proton resonances (Figure S8). This can be eliminated by the addition of polar solvents such as DMSO, or by protonation or deprotonation. For $\mathbf{2}$, aggregation is substantially eliminated at concentrations suitable for UV-vis (see Figure S7) and a typical acene vibronic structure was observed as shown in Figure 2 (a shoulder in the UV-vis spectrum at $705 \mathrm{~nm}$ suggests the presence of small quantities of either monoanion or aggregates). Protonation of $\mathbf{1}$ with TFA is complete after addition of one equivalent of acid (Figure 3, Figures S9, S10) and results in a hypsochromically shifted absorption spectrum with a $\lambda_{\max }$ of $575 \mathrm{~nm}$ for $\mathbf{2}$ in acetonitrile, and vibronic structure typical of acenes. Deprotonation (Figure 3) occurs using relatively weak bases such as DMAP or TEA leading to a bathochromically shifted absorption spectrum with a $\lambda_{\max }$ of $714 \mathrm{~nm}$ in methanol (for 1) still with a characteristic acene vibronic structure. Deprotonation was confirmed by titration which fit well to a 1:1 process irrespective of the type of base used (for example, see Figure 3b, Figures S11, S12), and also by back titration with TFA where one equivalent was required to revert back to the spectrum of the neutral species. Surprisingly, deprotonation also occurs by dissolution in proton accepting solvents such as DMSO as evidenced by the significantly redshifted absorption $\lambda_{\max }$ of $737 \mathrm{~nm}$ for $\mathbf{1}$, which was not further deprotonated by addition of DMAP or TEA, and a two-step protonation upon reverse titration with methanesulfonic acid (see Figure S13, S14). The excitation spectrum of the deprotonated species is also identical to its absorption spectrum, again indicating a single predominant fluorescent species (Figure S15). Protonated species behave similarly (Figure $\mathrm{S} 16$ ). $\mathrm{p} K_{\mathrm{a}}$ values of $\mathbf{2}$ were estimated by UV-vis titration of $\mathbf{2}$ with methanesulfonic acid (MSA) or DMAP in acetonitrile $(\mathrm{MeCN})$ at $25{ }^{\circ} \mathrm{C}$. This approach yields two $\mathrm{p} K_{\mathrm{a}}(\mathrm{MeCN})$ values for $2: \mathrm{p} K_{\mathrm{a} 1}(\mathrm{MeCN})=12.4$ and $\mathrm{p} K_{\mathrm{a} 2}(\mathrm{MeCN})=20.8$. These values (relative to $\mathrm{pK}_{\mathrm{s}}(\mathrm{MeCN})$ ) indicate, respectively, that monoprotonation and monodeprotonation are relatively easy processes for $\mathbf{2}$ in $\mathrm{MeCN}$.

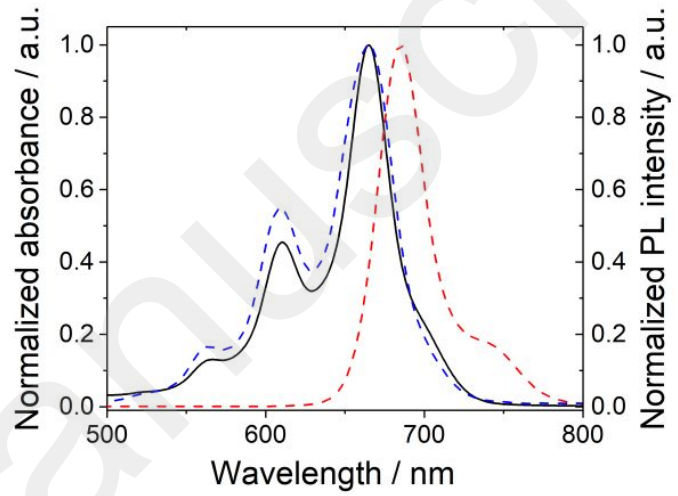

Figure 2. Electronic absorption spectroscopy of 2. UV-vis (solid black line), fluorescence emission (dashed red line) and excitation $\left(\lambda_{\mathrm{EX}}=690 \mathrm{~nm}\right.$, dashed blue line) spectra in THF.
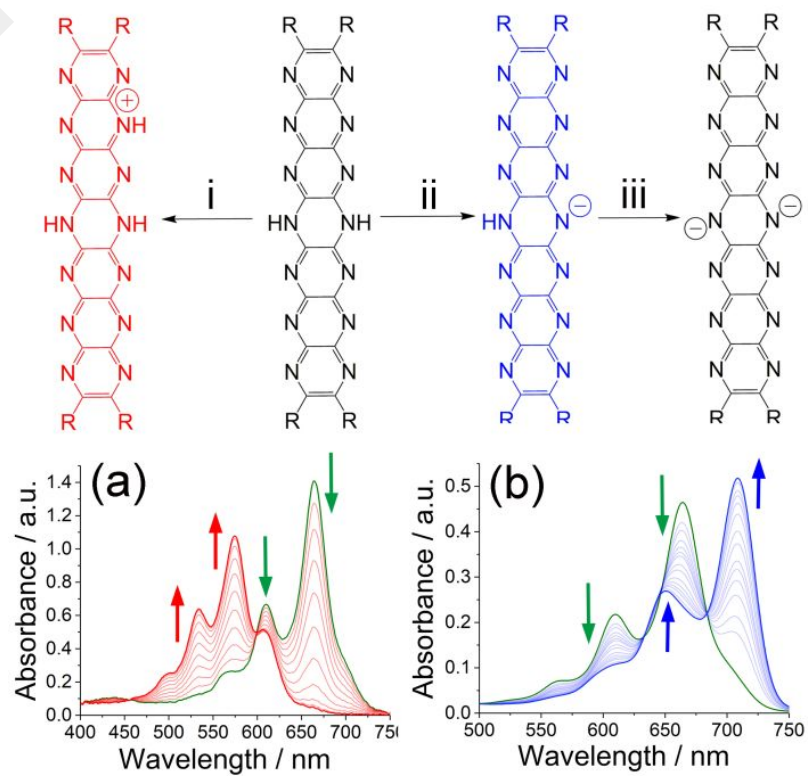

Figure 3. Prototropic reactions of $\mathrm{N}_{14} \mathrm{Hp}$ with (i) trifluoroacetic acid (proton at computationally most stable position), (ii) 4dimethylaminopyridine (4-DMAP), (iii) lithium bis(trisilyl)amide. Color of the structures correspond to the endpoints of titrations shown in (a, b). (a) UV-vis titration with TFA. (b) UV-vis titration with 4-DMAP in acetonitrile. Arrows indicate variations in absorbance during titration. 
The gas-phase deprotonation enthalpy (DPE) was calculated using the semi-empirical AM1 method as implemented in the Spartan '14 program (see Supporting Information). Compound 1 has a calculated DPE of $311.3 \mathrm{kcal} / \mathrm{mol}$ similar to that of the highly nitrogenated, electron deficient tetrapyrazinoporphyrazine $(316.1 \mathrm{kcal} / \mathrm{mol})$, which readily deprotonates upon dissolution in DMSO. ${ }^{13}$ To effect further deprotonation, the use of a large excess of hydroxide or more strongly basic lithium bis(trimethylsilyl)amide is necessary and results in the formation of the doubly deprotonated species with a $\lambda_{\max }=741 \mathrm{~nm}$ in THF (compound 1, see Figure S17). The difficult second deprotonation of $\mathbf{1}$ is consistent with its high calculated DPE of $743.8 \mathrm{kcal} / \mathrm{mol}$. Overall, the optical gap of these materials can be effectively tuned from around $2.2 \mathrm{eV}$ to computed using time-dependent density functional theory (TD-DFT) (see Supporting Information). Despite being hypsochromically shifted compared to the observed spectra (ca. 80-100 nm (ca. $0.35 \mathrm{eV}$ )), they confirm the experimentally observed trend upon deprotonation. $\lambda_{\max }$ at $550 \mathrm{~nm}(2.25 \mathrm{eV})$, for neutral 3, $618 \mathrm{~nm}(2.08 \mathrm{eV})$ for anion [3- H] $]^{-}$and $664 \mathrm{~nm}$ $(1.87 \mathrm{eV})$ for the dianion $[3-2 \mathrm{H}]^{2-}$ are predicted with intense absorption bands almost exclusively involving HOMO-LUMO electronic transitions (Table S3). The small Stokes shift of ca. 20-30 nm observed experimentally (Figure $2 \mathrm{a}$ ) is reproduced in the computed emission bands with $\lambda_{\max }(\mathrm{em})$ of $585 \mathrm{~nm}(2.12$ $\mathrm{eV})$, for $3,654 \mathrm{~nm}(1.90 \mathrm{eV})$ for $[3-\mathrm{H}]^{-}$and $695 \mathrm{~nm}(1.78 \mathrm{eV})$ for $[3-2 \mathrm{H}]^{2-}$ (Table S3). DFT modeling of the protonated species $[3 \mathrm{H}]^{+}$also predicts a decrease in the HOMO-LUMO gap

Table 1. Photophysical Properties of 1 and 2 including Photoluminescence Quantum Yields, $\Phi_{\mathrm{PL}}$

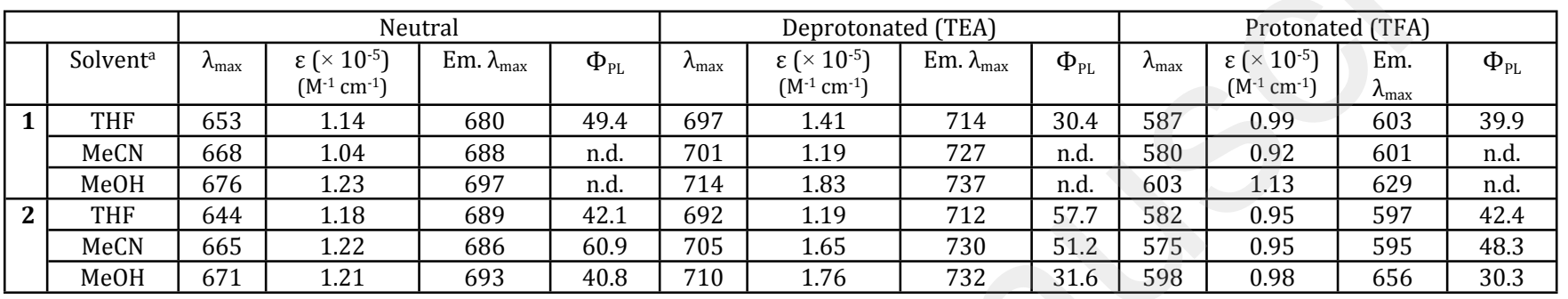

${ }^{\mathrm{a}} \mathrm{THF}$ : tetrahydrofuran; $\mathrm{MeCN}$ : acetonitrile; $\mathrm{MeOH}$ : methanol.

$1.6 \mathrm{eV}$ by protonation, neutralization or deprotonation.

Photoluminescence quantum yields (PLQYs) of the compounds (Table 1) were measured in different solvents. Generally, PLQYs are higher prior to treatment with acid or base. Compound 2 exhibits a large PLQY of $61 \%$ in acetonitrile with fluorescence $\lambda_{\max }=686 \mathrm{~nm}$. Deprotonation (in acetonitrile) results in a reduced PLQY (51\%), and a bathochromic shift of emission further into the NIR region with a $\lambda_{\max }=730 \mathrm{~nm}$. Although deprotonation results in a slight decrease in PLQY, the extinction co-efficient at $\lambda_{\max }$ is increased somewhat from $1.22 \times 10^{5}$ to $1.65 \times 10^{5} \mathrm{M}^{-1} \mathrm{~cm}^{-1}$. The protonated species is less fluorescent than either the neutral species or the deprotonated species with a PLQY of $48 \%$.

Density functional theory (DFT) calculations were performed at the B3LYP/def2-TZVP level of theory on the $\mathrm{N}_{14} \mathrm{Hp}$ compound 3 (Figure 1) where t-butyls of 1,2 were replaced with hydrogen atoms (Figure S18), in order to investigate quantitatively their structural and photophysical properties. The computed optimized ground state molecular structure of $\mathbf{3}$ matches well the crystal structure of 2 (see Figure S19), including the planarity at 7,16-dihydropyrazine group, dissymmetry in the $\mathrm{C}-\mathrm{N}$ bond lengths of the backbone, and the orientation of phenyl groups. HOMO and LUMO structures of $\mathbf{3}$, which are energetically isolated from the other occupied and vacant MOs, are largely delocalized over the molecule having respectively $\pi$ - and $\pi *$-type characteristics (Figure 4 ), and present a HOMO-LUMO gap of $2.5 \mathrm{eV}$. This gap is strongly attenuated for single and double deprotonations $(2.06 \mathrm{eV}$ for the anion $[3-\mathrm{H}]^{-}$and $1.75 \mathrm{eV}$ for the dianion $[3-2 \mathrm{H}]^{2-}$, (Figure S18, Figures S20, S21). Single protonation yields several possible tautomers (Figure S18, S22) and a HOMO-LUMO gap of $1.57 \mathrm{eV}$ was obtained for the computationally most stable tautomer cation $[3 \mathrm{H}]^{+}$with comparable HOMO-LUMO gaps computed for other tautomers. Absorption spectra of the neutral and deprotonated models in the gas phase were and a bathochromic shift in absorption relative to the neutral species with a strong absorption band at $849 \mathrm{~nm}(1.46 \mathrm{eV})$ at the lowest energies (Table S3). These findings are not consistent with experiments, which suggest an increase in HOMO-LUMO gap. This inconsistency could be due to counterion effects, tautomerism or aggregation. NucleusIndependent Chemical Shifts $\left(\mathrm{NICS}_{\text {iso }}(0),{ }^{14}\right.$ Figure S23, S24) reveal a distribution of aromaticity on the $\mathrm{N}_{14} \mathrm{Hp}$ core in $3{ }^{15,16}$

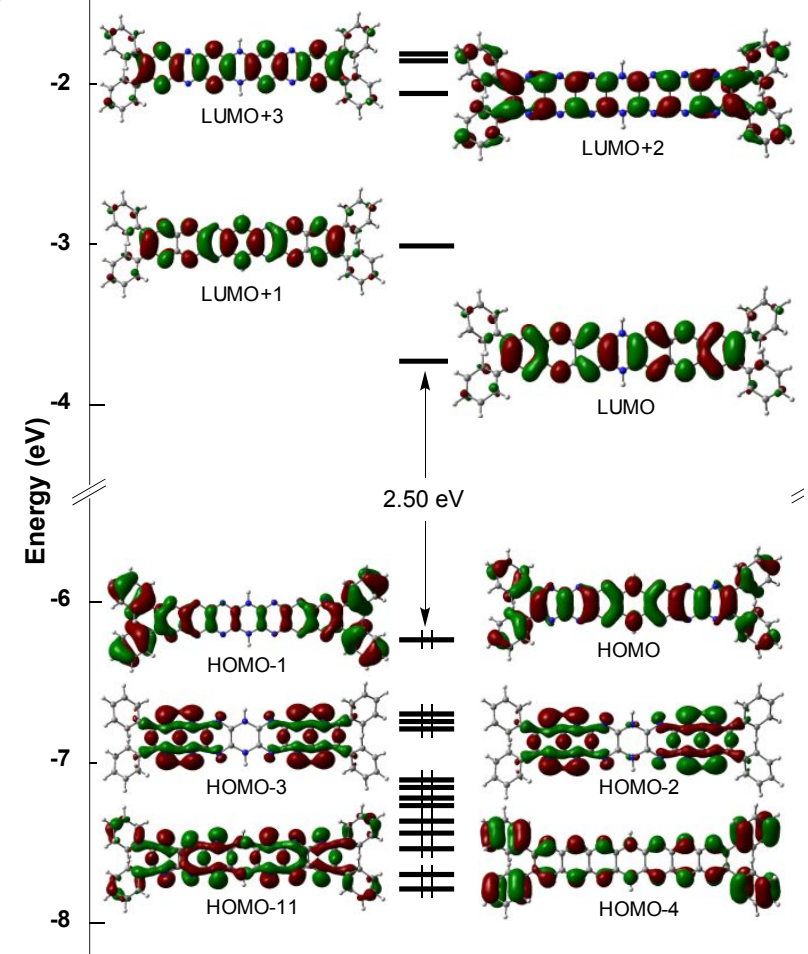

Figure 4. Calculated HOMO-LUMO molecular orbital structures of the model chromophore 3 . Contour values are \pm 0.03 $\left(\mathrm{e} / \mathrm{bohr}^{3}\right)^{1 / 2}$. 
Although 2 can be obtained unaggregated in solution, the state and stability of $\mathbf{2}$ in films and solution was investigated. Compound $\mathbf{2}$ is stable indefinitely (years) under ambient dark storage conditions. When deposited on quartz substrate, 2 exhibits UV-vis spectra similar to those in non-polar solvents (i.e., aggregated, Figure S6, S25). Exposure of this film to acidic (TFA) or basic (TEA) vapor results in shifts of the UV-vis absorption maximum similar to those observed in solution suggesting formation respectively of monocation or monoanion in the aggregate films (Figure S26). Films of 2 exposed to direct sunlight were stable for several days with apparent gradual conversion to monocation (Figure S27(a)). Exposure to high intensity light from a $\mathrm{Hg}$-Xe lamp leads to similar changes (Figure S27(c)) while, in $\mathrm{CH}_{2} \mathrm{Cl}_{2}$ solution, 2 undergoes rapid protonation followed decomposition (Figure S27(d)).

In summary, we report the synthesis of tetradecaazapyrazinacenes as an unprecedented class of long wavelength emissive chromophore with amphiprotic properties. The present work demonstrates that higher pyrazinacenes such as $\mathbf{1}$ and $\mathbf{2}$ are highly effective chromophores for NIR emission applications having excellent quantum yields of emission at $700 \mathrm{~nm}$. The polar $\mathrm{N}_{14} \mathrm{Hp}$ core with dihydropyrazine is stable even when deprotonated (does not autoxidize) and can be synthetically modified. These compounds are essentially monovalently amphiprotic undergoing single protonation/deprotonation (although double deprotonation is also possible). We are currently preparing other derivatives of the $\mathrm{N}_{14} \mathrm{Hp}$ core for use as bioimaging agents with the expectation that the oligopyrazine unit will lead to unique opportunities for selective imaging.

\section{ASSOCIATED CONTENT}

\section{Supporting Information}

The Supporting Information is available free of charge on the ACS Publications website at DOI: .

Details of synthesis, Cifs for 2.(DMAP) $)_{2}$ and the triethylamine solvate. Additional spectroscopic data. Computational methods. Plots of the computed compounds, selected DFToptimized bond distances for 3, DFT molecular orbital diagrams, NICS and TD-DFT data for $[3-\mathrm{H}]^{-},[3-2 \mathrm{H}]^{2-}$, and $[3 \mathrm{H}]^{+}$.

\section{AUTHOR INFORMATION}

\section{Corresponding Authors}

*richards.gary.james@ocha.ac.jp

*jonathan.hill@nims.go.jp

\section{ORCID}

Gary J. Richards: 0000-0002-5262-2587

Shinji Yamada: 0000-0002-5945-5996

Whitney A. Webre: 0000-0002-4777-2855

Paul A. Karr: 0000-0003-3560-2178

Jan Labuta: 0000-0002-8329-0634

Katsuhiko Ariga: 0000-0002-2445-2955

Francis D'Souza: 0000-0003-3815-8949

Jean-François Halet: 0000-0002-2315-4200

Jonathan P. Hill: 0000-0002-4229-5842

\section{Notes}

The authors declare no competing financial interests.

\section{ACKNOWLEDGMENT}

This work was partly supported by World Premier International Research Center Initiative (WPI Initiative), MEXT, Japan, JSPS KAKENHI Grant No. JP15K13684 (Linear acene proton conductors for molecular electronics), JSPS KAKENHI Grant No. JP16H06518 (Coordination asymmetry), and CREST JST, Japan (Grant No. JPMJCR1665). A.C., S.K., and J.-F.H. are grateful to GENCI (Grand Equipment National de Calcul Intensif) for HPC resources (Grant A0050807367). These studies were also facilitated within the scope of the France Japan International Collaboration Framework through the Laboratory for Innovative Key Materials and Structures (UMI 3629 LINK), financially supported by Saint-Gobain, Centre National de la Recherche Scientifique (CNRS), Université de Rennes 1 (UR1), and National Institute for Materials Science (NIMS). This work was financially supported by the National Science Foundation (Grant No. 1401188 to FD).

\section{REFERENCES}

(1) Richards, G. J.; Hill, J. P.; Subbaiyan, N. K.; D’Souza, F.; Karr, P. A.; Elsegood, M. R. J.; Teat, S. J.; Mori, T.; Ariga, K. Pyrazinacenes: aza analogues of acenes. J. Org. Chem., 2009, 74, 8914-8923.

2. Richards, G. J.; Hill, J. P.; Mori, T.; Ariga. K. Putting the 'N' in acene: pyrazinacenes and their structural relations. Org. Biomol. Chem. 2011, 9, 5005-5017

(3) Švec, P.; Webre, W.; Richards, G. J.; Labuta, J.; Wakayama, Y.; Miklík, D.; Karr, P. A.; Mori, T.; Ariga, K.; D’Souza, F.; Hill, J. P. Phenanthroline-fused pyrazinacenes: One-pot synthesis, tautomerization and a $\mathrm{Ru}^{\mathrm{II}}\left(2,2^{\prime}-\text {-bpy }\right)_{2}$ derivative. Eur. J. Inorg. Chem., 2018, 22, 2541-2548.

(4) Escobedo, J. O.; Rusin, O.; Lim, S.; Strongin, R. M. NIR dyes for bioimaging applications. Curr. Opin. Chem. Biol. 2010, 14, 64-70.

(5) Barbieri, A.; Bandini, E.; Monti, F.; Praveen, V. K.; Armaroli, N. The rise of near infrared emitters: organic dyes, porphyrinoids and transition metal complexes. Top. Curr. Chem., 2016, 374, 1-39.

(6) Baggaley, E.; Weinstein, J. A.; Williams, J. A. G. Lighting the way to see inside the lice cell with luminescent transition metal complexes. Coord. Chem. Rev. 2012, 256, 1762-1785.

(7) Porcu, E. P.; Salis, A.; Gavini, E.; Rassu, G.; Maestri, M.; Giunchedi, P. Indocyanine green delivery systems for tumour detection and treatments. Biotechnol. Adv., 2016, 34, 768-789.

(8) Lu, H.; Mack, J.; Yang, Y.; Shen, Z. Structural modification strategies for the rational design of red/NIR region BODIPYs. Chem. Soc. Rev. 2014, 43, 4778-4823.

(9) Ogata, F.; Nagaya, T.; Maruoka, Y.; Akhigbe, J.; Meares, A.; Lucero, M. Y.; Satraitis, A.; Fujimura, D.; Okada, R.; Inagaki, F.; Choyke, P. L.; Ptaszek, M.; Kobayashi, H. Activatable near-infrared fluorescence imaging using PEGylated bacteriochlorin-based chlorin and BODIPYdyads as probes for detecting cancer. Bioconjugate Chem. 2019, 30, 169-183.

(10) Donald D. S. Tetraaminopyrazine, 2,3,5-triamino-6nitropyrazine and 2,6-diamino-3,5-dinitropyrazine. 1974. US 3808209A (accepted patent).

(11) Mondal, R.; Shah, B. K.; Neckers, D. C. Photogeneration of heptacene in a polymer matrix. J. Am. Chem. Soc., 2006, 128, 9612-9613.

(12) R. Scipioni, R.; Boero, M.; Richards, G. J.; Hill, J. P.; Ohno, T.; Mori, T.; Ariga, K. Tautomerism in reduced pyrazinacenes. J. Chem. Theory Comput., 2010, 6, 2517-525.

(13) Stuzhin, P. A.; Malyasova, A. S.; Sheinin, V. B.; Kokareva, E.; Tarakanov, P. A.; Koifman, O. I. Acid-base properties of tetrapyrazinoporphyrazines. $1 . \quad$ Deprotonation of octaethyltetrapyrazinoporphyrazine in $\mathrm{CH}_{2} \mathrm{Cl}_{2}$, THF, DMSO and pyridine. The crucial role of water. Dyes Pigm., 2017, 139, 509-516.

(14) Chen, Z.; Wannere, C. S.; Corminboeuf, C.; Puchta, R.; Schleyer, P. v. R. Nucleus-independent chemical shifts (NICS) as an aromaticity criterion. Chem. Rev. 2005, 105, 3842-3888.

(15) Miao, S.; Brombosz, S. M.; Schleyer, P. v. R.; Wu, J. I.; Barlow, S. Marder, S. R.; Hardcastle, K. I.; Bunz, U. H. F. Are N,Ndihydrodiazatetracene derivatives antiaromatic? J. Am. Chem. Soc., 2008, 130, 7339-7344. 
(16) Wu, J. I.; Wannere, C. S.; Mo, Y.; Schleyer, P. v. R; Bunz, U. H. F. 4n $\pi$ Electrons but stable: N,N-Dihydrodiazapentacenes. J. Org. Chem., 2009, 74, 4343-4349.

2 

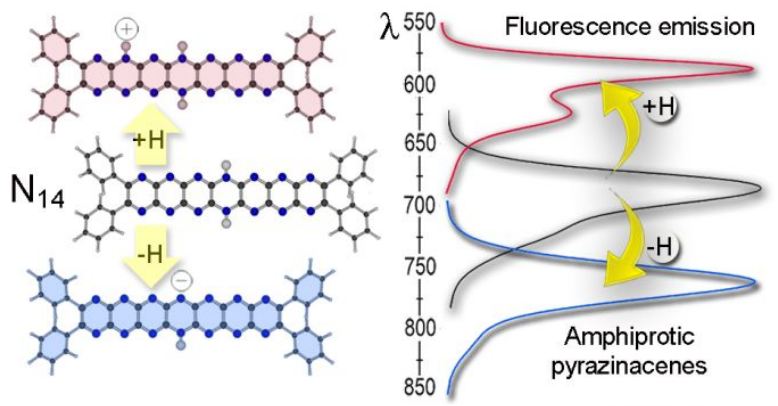